\title{
DIFFERENCES IN THE PREDATORY BEHAVIOUR OF MALE AND FEMALE LADYBIRD BEETLES (COCCINELLIDAE)
}

\author{
JAN ŠIPOŠ $\check{1}^{1,4, *}$, EMMA KVASTEGÅRD ${ }^{3}$, KWABENA OWUSU BAFFOE ${ }^{3}$, \\ KAWSHAR SHARMIN ${ }^{3}$, ROBERT GLINWOOD ${ }^{3}$, and PAVEL KINDLMANN ${ }^{1,2}$ \\ ${ }^{1}$ Department of Biodiversity Research, Global Change Research Centre AS CR, Na Sádkách 7, 37005 České Budějovice, Czech Republic \\ ${ }^{2}$ Institute of Environmental Studies, Charles University, Benátská 2, CZ-12801 Prague 2, Czech Republic \\ ${ }^{3}$ Faculty of Natural Resources and Agricultural Sciences, Department of Ecology, Swedish University of Agricultural Sciences, \\ Box 7044, 75007 Uppsala, Sweden \\ ${ }^{4}$ Department of Ecology and Environmental Sciences, Faculty of Science, Palacky University, 17. listopadu, 77146 Olomouc, Czech Republic \\ *Corresponding author: jsipos@seznam.cz
}

\section{ABSTRACT}

\begin{abstract}
We investigated the response of males and females of ladybirds to different densities of aphids. This was studied using Coccinella septempunctata as the predator and Rhopalosiphum padi as the prey. Interactions between this ladybird and prey were observed on barley (Hordeum vulgare). We established aphid colonies on barley at three different densities, 16, 32 and 84 aphids per pot. Adult ladybirds placed in these colonies were then observed for 10 minutes or until they flew away. We hypothesized that females should consume more aphids than males per unit time. The results of this experiment revealed that the risk of aphid mortality per plant depended on the sex of the ladybird beetle. Female ladybirds consumed significantly more aphids than males per unit time. In addition the turning rate and time spent resting differed between the sexes.
\end{abstract}

Keywords: Coccinella septempunctata, functional response, foraging, aphids

\section{Introduction}

Several factors influence the rate at which predators catch and consume prey (Maisonhaute and Lucas 2011; Navodita et al. 2011) and one of the most important is prey density (Ives et al. 1993; Yasuda 1995; Yasuda and Ishikawa 1999). Results of experiments on predation rate indicate a positive response of predation to aphid density (Dixon 1959; Sinha et al. 1982; Carter et al. 1984; Rotheray 1989; Kindlmann and Rủžička 1992; Ives et al. 1993). Similarly experimental studies on biological control also record a positive effect of aphid density on predation and oviposition behaviour of ladybirds (Obrycki and Kring 1998; Iperti 1999; Kindlmann and Dixon 1997; Das and Dixon 2011). Other studies, however, indicate that the response of individual lady beetles to aphid density is extremely weak and only becomes detectable at the population level (Ives et al. 1993). Positive relationships between density of aphids and ladybird activity confirm the results of experiments on the aggregation behaviour of coccinellids (Frazer and Raworth 1985; Evans and Youssef 1992; Iperti 1999; Schellhorn and Andow 2005).

Difference in the predatory activity of males and females is widely reported but has not been studied in detail in ladybirds (Hemptinne et al. 1996; Dixon 2000). There are few studies comparing the behaviour (turning rate) associated with the differences in the predatory behaviour of two sexes (Gründbaum 1998; Dixon 2000). Differences in their predatory behaviour are to be expected because males and females have different life history strategies (Stearns 1989; Stearns 1992; Hemptinne et al.
1996). Females have to obtain sufficient energy over and above that required to maintain themselves to be able to produce eggs, find suitable oviposition sites and lay the maximum number of eggs (Matsura and Morooka 1983; Muthukrishnan and Pandian 1987). This indicates that females need to spend more time foraging than males (Muthukrishnan and Pandian 1987; Kerr 2008). Honek (1985) has shown that sexes in ladybirds differ in their foraging behaviour.

It is assumed that the sexes in ladybirds differ in the rate at which they catch and consume prey. To test this hypothesis we measured the predation rate of males and females in different sized colonies of aphids. In addition, we also recorded whether the sexes spent the same amount of time foraging and resting.

\section{Materials and Methods}

\section{Plants and insects}

Barley ( $H$. vulgare) was grown in a controlled environment room at $20^{\circ} \mathrm{C} \pm 1$ with a L16: $\mathrm{D} 8$ photoperiod. Bird cherry-oat aphid, Rhopalosiphum padi, was reared on barley (cv. Golf) in multi-clonal cultures in a glasshouse at $20^{\circ} \mathrm{C} \pm 1$, with a L16: D8 photoperiod and supplementary lighting. Adult Coccinella septempunctata were originally collected from natural habitats close to Uppsala, Sweden $\left(59^{\circ} 47^{\prime} \mathrm{N}\right.$ and $\left.17^{\circ} 39^{\prime} \mathrm{E}\right)$ and reared for several generations before they were used in the experiments. They were reared in culture in cages with $R$. padi 
on barley (cv. Golf) and flowering oilseed rape, Brassica napus L., as a source of pollen at $21^{\circ} \mathrm{C} \pm 1$, a photoperiod of L16 : D8 and relative humidity of $60 \pm 10 \%$. Insects used in the experiments were adults.

\section{Experimental design}

This experiment aimed to determine the effect of aphid density on predatory behaviour. Different numbers of aphids (84, 32 and 16) were placed on 4 barley seedlings. Ten barley seeds were planted per pot and later thinned out, so that there were 4 plants per pot. Cylindrical tubes were placed over the plants in each pot to prevent the aphids from dispersing and so keeping the number of aphids per plant constant.

As model species we chose the ladybird Coccinella septempunctata as the predator and the aphid, Rhopalosiphum padi, feeding on barley, Hordeum vulgare, as the prey. There were 20 replicates of each treatment. Each replicate consisted of a pot with same number of plants but different numbers of prey. Altogether 60 pots were used per experiment. For each replicate we randomly chose one ladybird, which was placed at the base of a randomly chosen plant. Different ladybirds and different plants were used in each replicate to avoid pseudoreplication. Ladybirds were then observed for 10 minutes or until they flew away. The sexes of the ladybirds were determined at the end of each replicate (Baungaard 1980). Also the number of aphids in a pot was counted at the end of the observation time. The predators were starved with access to water for 24 hours before using them in the experiment. Each treatment was observed on the same day to avoid the effect of different weather conditions on the results. Each experiment was divided into two days. Because of this, the predators used on the second day were starved for 48 hours. Only nymphs of aphids were placed on the plants. Aphids were allowed to settle and form colonies similar to those observed in the field for twenty four hours prior to the experiment.

\section{Sampling method}

We used focal sampling and continuous recording (Grevstad and Klepetka 1992; Clark and Messina 1998), which involved observing one individual for a specified amount of time and recording several different categories of behaviour. The following behaviours were observed: a) killing; b) consumption of aphids; c) resting; d) turning; e) position where the aphids were killed (stem, leaf, ground); f) giving-up time. We transformed certain types of behaviours into proportions (Predation rate $=$ No. of aphids consumed $/ 600$ s, Resting = time spent resting/600s, Turning $=$ No. of turns $/ 600 \mathrm{~s}$, Average aphids per plant = total No. of aphids per pot/number of plants per pot, Risk of mortality = total No. of aphids killed / total No. of aphids per pot, Time spent in patch = time spent in the patch/600s). We measured the different types of behaviour differently. The behaviours that can be specified as events (behaviour of short duration) were recorded as number of events per unit time. The states that are behaviour patterns with a long duration were measured as proportion of time spent performing the activity.

\section{Data analysis}

The GLM ANOVA with type II sum of squares was used to test if the relationships between the variables were significant (Schellhorn and Andow 2005). Dependent variables were proportions hence binomial distribution with link function log in GLM was used. Suitability of particular models was examined using residual statistics. For assessing statistical significance we used the Wald test with a chi-square distribution. $\mathrm{R}$ statistical software was used for the data analysis (R Development Core Team, 2009). To obtain linearly independent data the proportions were logarithmically transformed. Each experiment was divided into two days because of the time constraint. Therefore, we have to be aware of variability connected with the different days. This means that the results for each experiment are nested within two days.

\section{Results}

The fewer aphids there were per pot, the greater was the probability that an individual will be captured by a predator (Fig. 1). The risk of mortality depended significantly on the number of aphids per pot $\left(\chi^{2}=6.45\right.$; $\mathrm{df}=1 ; \mathrm{df}_{\text {resid. }}=57 ; \mathrm{p}=0.011$ ) (Fig. 1) and was highest in the treatment with the lowest number of aphids per pot and lowest in the treatment with the highest number of aphids per pot.

The relationship between risk of aphid mortality and number of aphids per plant was different for the sexes (Fig. 1). Females appeared to search more effectively than males when there were fewer aphids per plant $\left(\chi^{2}=9.55\right.$; $\left.\mathrm{df}=2 ; \mathrm{df}_{\text {resid. }}=56 ; \mathrm{p}=0.008\right)$. The proportion of total aphid deaths was lowest on the ground, intermediate on the leaf and highest on the stem (Fig. 2). There was a significant difference between the sexes concerning the proportion of aphids killed on different parts of the plants $\left(\chi^{2}=0.23\right.$; $\left.\mathrm{df}=3 ; \mathrm{df}_{\text {resid. }}=176 ; \mathrm{p}=0.63\right)$. From Fig. 3 it can be seen that the females killed significantly more aphids per unit time than males only on plants with highest numbers of aphids $\left(\chi^{2}=6.73 ; \mathrm{df}=1 ; \mathrm{df}_{\text {resid. }}=18 ; \mathrm{p}=0.018\right)$. There was a significant difference in the frequency of turning of the two sexes (Fig. 4), females turned more frequently than males $\left(\chi^{2}=4.41 ; \mathrm{df}=1 ; \mathrm{df}_{\text {resid. }}=57 ; \mathrm{p}=0.036\right)$ and males spent more time resting than females $\left(\chi^{2}=3.95 ; \mathrm{df}=1\right.$; $\mathrm{df}_{\text {resid. }}=57 ; \mathrm{p}=0.042$ ) (Fig. 5). Fig. 5 shows that both sexes spent significantly more time on the plants if previously subjected to a long period of starvation $\left(\chi^{2}=3.69 ; \mathrm{df}=1\right.$; $\left.\mathrm{df}_{\text {resid. }}=57 ; \mathrm{p}=0.049\right)$. Analysing the period of time spent on the plants revealed that male residence time, unlike that of females, significantly varied in relation to hunger level ( $\left.\chi^{2}=8.87 ; \mathrm{df}=1 ; \mathrm{df}_{\text {resid. }}=33 ; \mathrm{p}=0.005\right)$ (Fig. 6). 


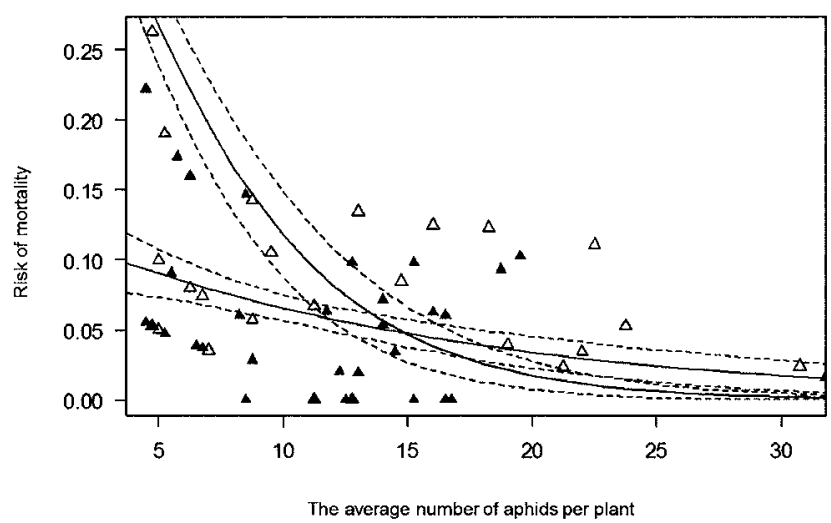

Fig. 1 Differences between the sexes (male = grey line and female $=$ black line) in the risk of mortality (Risk of mortality expressed as total number of kills/total number of aphids in the pot per study period) vs. average number of aphids per plant. Dashed lines indicate the SE.
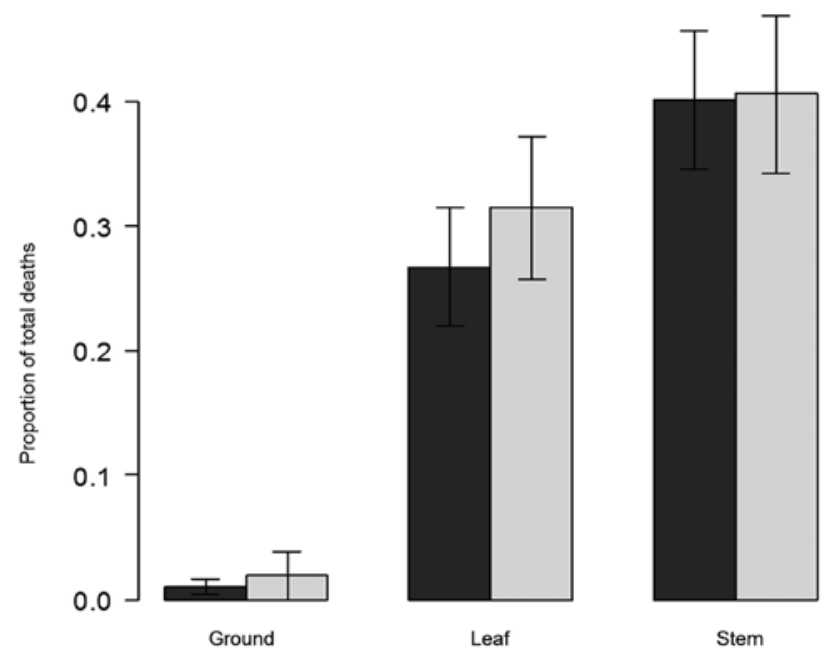

Fig. 2 Barplot of the proportion of total aphid deaths that occurred on the ground and on the leaves and stems of the plants searched by male (black) and female (grey) ladybirds. The bars show the SE.
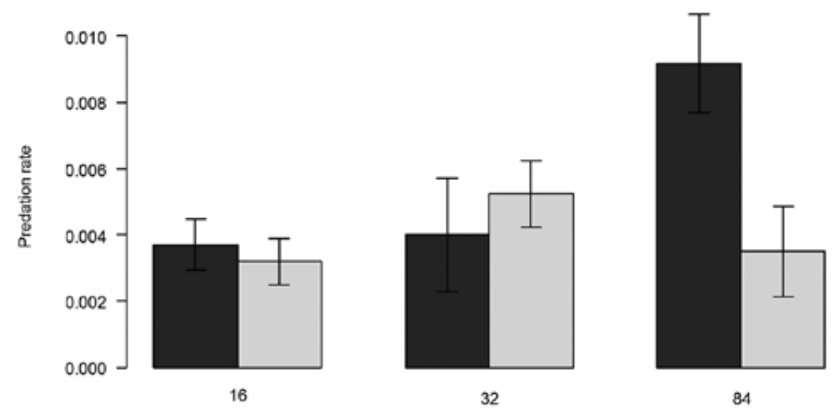

Abundance of aphids

Fig. 3 The numbers of aphids killed (rate of predation) when male or female ladybirds were released on plants infested with one of three different densities of aphids (16, 32 and 84 aphids per pot). The bars show the SE.

\section{Discussion}

The results presented confirm that female ladybirds are more active and consume significantly more aphids

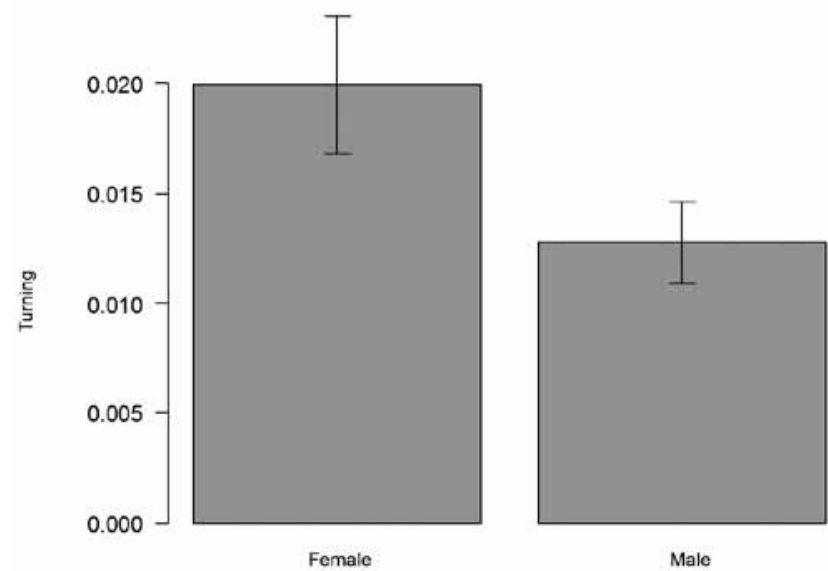

Fig. 4 Turning rates (turning is expressed as a number of turns per study period) recorded for male and female ladybirds. The bars show the SE.

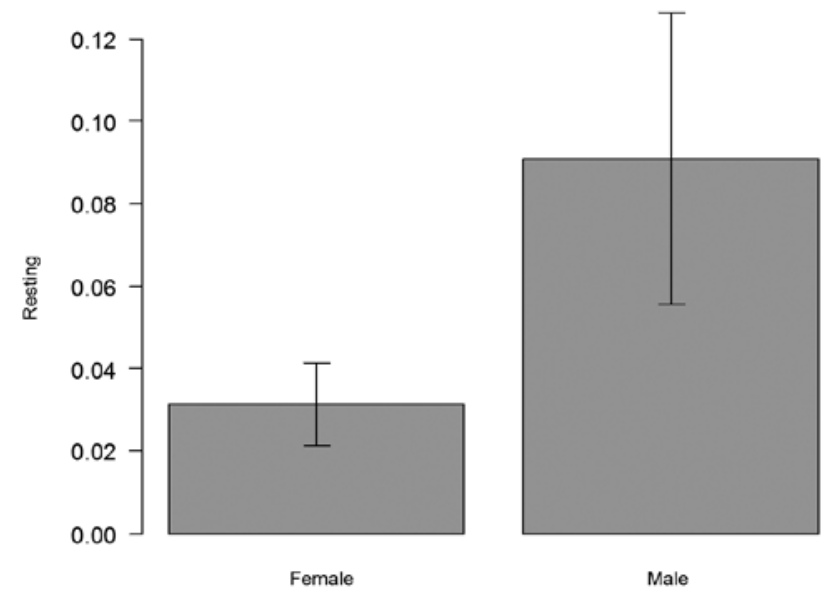

Fig. 5 The length of time spent resting (resting is expressed as a number of times observed resting per study period) by male and female ladybirds. The bars show the SE.
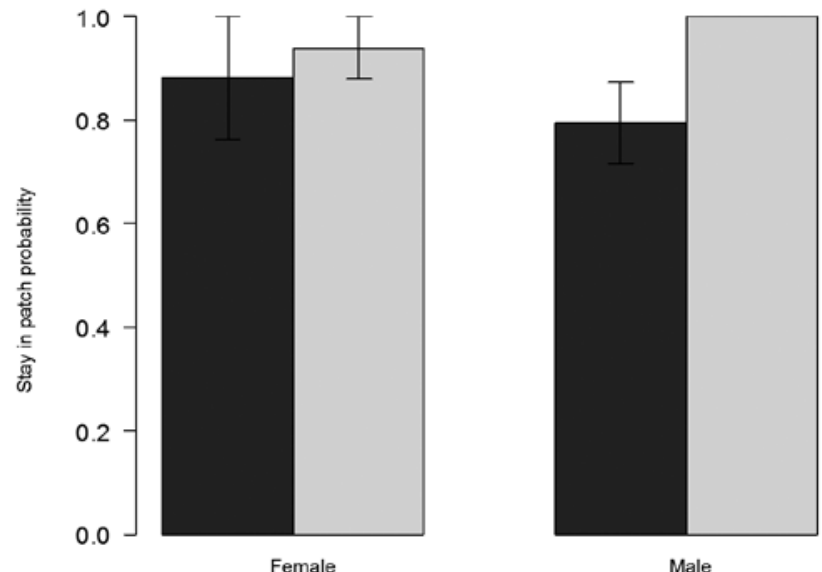

Fig. 6 Tendency for males and females to stay in a patch. The bars show SE. Black bar is for the first day and grey bar for the second day.

than males. According to Hemptinne et al. (1996) and Honek (1985) the searching behaviour of the sexes differ because the females search for favourable oviposition sites whilst the males search for females. Females have 
to obtain sufficient energy over and above that required to maintain themselves to be able to produce eggs, find suitable oviposition sites and lay as many eggs as possible (Matsura and Morooka 1983; Muthukrishnan and Pandian 1987; Allen et al. 1992). This indicates that females need to spend more time foraging for aphids than males, which only have to maintain themselves and search for mates.

The greatest difference in the proportion of kills occurred on the leaves, where the aphids seemed to be fairly evenly spread and of an intermediate abundance. Here, the females killed a larger proportion of the total aphids than males. In addition, the relationship between the risk of an aphid being killed and the number of aphids per plant depended on the sex of the ladybird. The females searched more actively at low prey densities than males. This suggests that females are better adapted to search or search more intensively for prey than males (Muthukrishnan and Pandian 1987; Hemptinne et al. 1996; Kerr 2008).

The results also indicate that adult ladybirds stayed longer in a patch when they had been starved for two days than when starved for one day. This longer residence time might be a result of the predator's need to satisfy their hunger (Muthukrishnan and Pandian 1987; Kerr 2008). However, with regards to gender, this could also be linked to the search for mates (Honek 1985; Hemptinne et al. 1996). Differences in the time spent in a patch by the sexes of ladybirds might be due to their different priorities (Stearns 1992). In the current study, the males on the first day were possibly not hungry and therefore searched for females instead of food and as a consequence spent less time in the patch (Honek 1985; Hemptinne et al. 1996). Their relatively longer stay in the patch on the second day might be because of their increased hunger level. The females on the other hand stayed for a relatively constant time in the patch, because they were actively searching for food to satisfy their hunger and need to mature eggs (Muthukrishnan and Pandian 1987; Allen et al. 1992; Hemptinne et al. 1996; Yoshitaka and Yoshimi 1999).

\section{Conclusions}

The results confirm that the predation rate of the sexes of ladybirds differ significantly. Aphids are at a greater risk of being eaten when females are foraging on a plant and this may be associated with their cost of reproduction. Females need to harvest more energy than males as they need to produce eggs, find a suitable oviposition site, lay as many eggs as possible and maintain themselves (Muthukrishnan and Pandian 1987). Turning rate, which indicates predatory activity, was higher in females. Males spent more time resting than females. This confirms that females are more active in searching for prey and therefore a greater threat to aphids than males.

\section{Acknowledgements}

This study was supported by Grant No. PrF_2010_021 from the Internal Grant Agency of Palacky University in Olomouc, grants No. LC 06073 and CzechGlobe - Global Change ResearchCentre, Reg. No. CZ.1.05/1.1.00/02.0073 from the Ministry of Education, Youth and Sports of the Czech Republic, by the Grant Agency of the Czech Republic grant No. 206/07/0811, and by the Institute of Environmental Technologies project No. CZ.1.05/2.1.00/03.0100. We thank Erika Qvarfordt and Elham Ahmed for their technical assistance.

\section{REFERENCES}

Allen JS, Yang Y, Knapp JL, Stansly PA (1992) Functional response, reproductive function and movement rate of a grazing herbivore: the citrus rust mite on the orange. Florida Entomologist 75: $72-83$.

Baungaard J (1980) A simple method for sexing Coccinella septempunctata L. (Coleoptera: Coccinellidae). Entomologiske Meddelser 48: 26-28.

Clark TL, Messina FJ (1998) Plant architecture and the foraging success of ladybird beetles attacking the Russian wheat aphid. Ent Exp Appl 86: 153-161.

Das BC, Dixon AFG (2011) Assessment of patch quality by aphidophagous ladybirds: Laboratory study on the minimum density of aphids required for oviposition. Eur J Env Sci 1: 57-60.

Dixon AFG (1959) An experimental study in the searching behaviour of the predatory coccinellid beetle Adalia decempunctata (L.). J Anim Ecol 28: 259-281.

Dixon AFG (2000) Insect predator-prey dynamics Ladybird beetles \& biological control. Cambridge University Press, Cambridge, United Kingdom.

Evans EW, Youssef NN (1992) Numerical responses of aphid predators to varying prey density among Utah alfalfa fields. J KS Entomol Soc 65: 30-38.

Frazer BD, Raworth DA (1985) Sampling for adult coccinellids and their numerical response to strawberry aphids (Coleoptera: Coccinellidae; Homoptera: Aphididae). Can Entomol 117: 153-161.

Grevstad FS, Klepetka BW (1992) The Influence of plant architecture on the foraging efficiencies of a suite of ladybird beetles feeding on aphids. Oecologia 92: 399-404.

Gründbaum D (1998) Using spatially explicit models to characterize foraging performance in heterogeneous landscapes. Am Nat 151: 97-115.

Hemptinne JL, Dixon AFG, Lognay G (1996) Searching behaviour and mate recognition by males of the two-spot ladybird beetle, Adalia bipunctata. Ecol Ent 21: 165-170.

Honek A (1985) Activity and Predation of Coccinella septempunctata adults in the field (Coleoptera: Coccinellidae). Z Ang Entomol 100: 399-409.

Iperti G (1999) Biodiversity of predaceous coccinellidae in relation to bioindication and economic importance. Agr Ecosyst Environ 74 : $323-342$.

Işikber AA (2005) Functional response of two coccinellid predators, Scymnus levaillanti and Cycloneda sanguinea, to the cotton aphid, Aphis gossypii. Turkish J Agr Forestry 29: 347-355.

Ives AR, Kareiva P, Perry R (1993) Response of a predator to variation in prey density at three hierarchical scales: lady beetles feeding on aphids. Ecology 74: 1929-1938. 
Kerr AM (2005) Behavior of web-invading spiders Argyrodes argentatus (Theridiidae) in Argiope appensa (Araneidae) host webs in Guam. J Arachnol 33: 1-6.

Kindlmann P, Růžička Z (1992) Possible consequences of a specific interaction between predators and parasites of aphids. Ecol Model 61: 253-265.

Kindlmann P, Dixon AFG (1999) Strategies of aphidophagous predators: lessons for modelling insect predator-prey dynamics. J Appl Ent 123: 397-399.

Obrycki JJ, Kring TJ (1998) Predaceous Coccinellidae in biological control. Ann Rev Entomol 43: 295-321.

Maisonhaute JE, Lucas E (2011) Influence of landscape structure on the functional groups of an aphidophagous guild: Active-searching predators, furtive predators and parasitoids. Eur J Env Sci 1: 41-50.

Matsura T, Morooka K (1983) Influences of prey density on fecundity in a mantis Paratenodera angustipennis (S.). Oecologia 56: 303-312.

Muthukrishnan J, Pandian TJ (1987) Relation between feeding and egg production in some insects. Animal Sci 96: 171-179.

Navodita M, Pervez A, Kumar A, Ramteke PW (2011) Duration of development and survival of larvae of Coccinella transversalis fed on essential and alternative foods. Eur J Env Sci 1: 24-27.
R Development Core Team (2009) R: A language and environment for statistical computing. R Foundation for Statistical Computing, Vienna, Austria. http://www.R-project.org.

Rotheray GE (1989) Aphid predators: insects that eat greenfly. The Richmond Publishing Great Britain.

Schellhorn NA, Andow DA (2005) Response of coccinellids to their aphid prey at different spatial scales. Pop Ecol 47: 71-76.

Sinha TB, Pandey RK, Singh R, Tripathi CPM, Kumar A (1982) The functional response of Coccinella septempunctata Linn., a coccinellid predator of mustard aphid, Lipaphis erysimi. Kalt Entomon 7: 7-10.

Stearns SC (1989) Trade-offs in life history evolution. Funct Ecol 3: $259-268$

Stearns SC (1992) The Evolution of Life Histories. Oxford University Press, USA.

Yasuda H, Ishikawa H (1999) Effect of prey density and spatial distribution on prey consumption of the adult predatory ladybird beetle. J Appl Ent 123: 585-589.

Yoshitaka N, Yoshimi H (1999) Effects of prey availability on longevity, prey consumption, and egg production of the insect predators Orius sauteri and O. tantillus (Hemiptera: Anthocoridae). Ann Entomol Soc Am 92: 537-541. 